\title{
Exploring Indian wheat genotypes for less Celiac disease toxic epitopes
}

Sneh Narwal*, Bunty Sharma, Ritu Saini, Ram Baran Singh, Om Prakash Gupta, Vanita Pandey, Sewa Ram and Gyanendra Pratap Singh

ICAR-Indian Institute of Wheat and Barley Research, Karnal, Haryana. India - 132001

Article history: Received: 21 May., 2019 Revised: 12 Jan., 2020 Accepted: 18 Jan., 2020

Citation: Narwal S, B Sharma, R Saini, RB Singh, OP Gupta, V Pandey, Sewa Ram and GP Singh 2020. Exploring Indian wheat genotypes for less Celiac disease toxic epitopes. Journal of Cereal Research 12(1):79-82. http://doi.org/10.25174/2582-2675/2020/89975

\section{*Corresponding author: E-mail: Sneh.Narwal@icar.gov.in}

(C) Society for Advancement of Wheat and Barley Research

Keywords: Celiac disease, Wheat, Toxicity, Gliadins Wheat is an important cereal having significant role in food and nutritional security of large part of human population in the world. Large numbers of end-products are be made from wheat because of the presence of unique proteins which when mixed with water form visco-elastic complex called gluten. However, around $1 \%$ of world population suffers from celiac disease (CD) worldwide whichvaries with sex, age and location.The disease occurs in individuals with specific genetic background (with HLA-DQ2 and DQ8)whichare intolerant to the gluten proteins (Gliadins and Glutenins) of not only wheat but also to the prolamins fractions of barley (hordiens), rye (secalins) and oats (avenins)(McAllister et al.,2019). An autoimmune response starts when these proteins bind to the T-cells of the susceptible individuals. As a result, the villi in the small intestine get flattened and the surface area for the nutrient absorption is highly reduced and leads to malnutrition and other gastrointestinal problems.No pharmacological treatment is available to gluten-intolerant patients, and a strict, life-long gluten-free diet is the only safe and efficient treatment available.A diet is called gluten free only if the gluten content is less than $20 \mathrm{ppm}$.

The pooled global prevalence of serology confirmed CD is $1.4 \%$, while biopsy confirmed prevalence is only $0.7 \%$. Children are more affected $(0.9 \%)$ than the adults $(0.5 \%)$ (Singh et al., 2018). In India, the serology confirmed $\mathrm{CD}$ toxicity has been reported more in northand northwestern parts as comparedtosouthern parts in India. This may be because of higher consumption of wheat inNorthern parts of India. For example, the mean daily intake of wheat is $455 \mathrm{~g} /$ day in North India and only 25g/day in Southern parts ofIndia (Ramakrishna et al., 2016). CD toxicity is mainly caused by the presence of glutamine and proline rich specific epitopes in gluten protein. In vitro and in vivo studies in rats and humans have shown that a 33-mer peptide from gliadin (LQLQPFPQPQLPYPQPQLPYPQPQLPYPQPQPF) is not digestible by gastric, pancreatic, and intestinal brush-border membraneendoproteases (Shan et al., 2002). This and similar peptides have been identified as the main stimulators of the inflammatory response.Development of wheat varieties with low or very less immunogenicity (low amount of CD toxic epitopes) can lead to reduced toxicity load in human beings.

Wheat germplasm has wide variation and there are chances of screening out genotypes with less immunogenicity (Spaenij-Dekkinget al., 2005). The identified genotypes can be used in breeding in reducing CD toxic epitopes in high yielding varieties. Many biotechnological and genetic engineering techniques like genome editing by CRISPER/Cas9, downregulation of gliadin genes by RNAihavealso been used to remove the toxic sequences from the wheat (Malamgoda et al., 2017). But the main issue with the removal of such sequences is to maintain the baking quality of the modified wheat genotypes. Recently, Pilolli et al.,(2019) presented a comprehensive approach for characterization of durum wheat genotypes to identify low gluten, lower toxicity along with conserved rheological properties and yield. Lately, enzyme therapy techniques have also been used to inactivate the antigenic protein just before food preparation (Scherf et al., 2018). The use of biodiversity, biotechnology and breeding may 
Table 1 Wheat varieties released in different years used for the study.

\begin{tabular}{|c|c|c|c|c|c|c|c|}
\hline \multicolumn{2}{|c|}{ Before 1960} & \multicolumn{2}{|c|}{$1961-80$} & \multicolumn{2}{|c|}{$1981-2000$} & \multicolumn{2}{|c|}{ After 2000} \\
\hline Variety & $\begin{array}{l}\text { Year of } \\
\text { Release }\end{array}$ & Variety & $\begin{array}{l}\text { Year of } \\
\text { Release }\end{array}$ & Variety & $\begin{array}{l}\text { Year of } \\
\text { Release }\end{array}$ & Variety & $\begin{array}{r}\text { Year of } \\
\text { Release }\end{array}$ \\
\hline A -206 & 1954 & DURGAPURA-65 & 1974 & AJANTA & 1983 & $\operatorname{COW}(\mathrm{W}) \mathrm{I}$ & 2006 \\
\hline BAXI-288-18 & 1952 & HD-1941 & 1972 & CPAN-1676 & 1984 & DBW-17 & 2007 \\
\hline C-281 & 1955 & HD-1949 & 1973 & DL-153-2 & 1985 & GW-322 & 2002 \\
\hline C-591 & 1934 & HD-2177 & 1980 & GW-40 & 1981 & HD-2888 & 2006 \\
\hline GULAB & & HD-2189 & 1980 & HD-2329 & 1985 & HI-1531 & 2006 \\
\hline JOB-666 & & HI-385 & 1976 & HI-977 & 1988 & HPW-251 & 2008 \\
\hline KENPHAD-25 & 1951 & HP-1102 & 1980 & HS-240 & 1989 & K0307 & 2007 \\
\hline KHARCHIA L & & HYB-65 & 1976 & K-8020 & 1987 & K-9644 & 2000 \\
\hline NI-345 & 1955 & K-68 & 1974 & KRL-1-4 & 1990 & MP-4010 & 2003 \\
\hline NP-12V & 1910 & KALYANSONA & 1969 & LOK-1 & 1982 & RAJ-4037 & 2004 \\
\hline NP-4 & 1905 & KHARCHIA-65 & 1970 & NARMADA112 & 1982 & VL-804 & 2002 \\
\hline NP-52 & 1920 s & LERMA ROJO & 1969 & NIAW-34 & 1997 & KRL-210 & 2012 \\
\hline NP-721 & $1949-50$ & NI-5439 & 1975 & PBW-343 & 1996 & DBW-39 & 2010 \\
\hline NP-761 & $1949-50$ & NI-917 & 1973 & PBW-65 & 1987 & DPW-621-50 & 2011 \\
\hline NP-771 & & PV-18 & 1969 & RAJ-3765 & 1996 & MACS-6222 & 2010 \\
\hline NP-809 & 1954 & SONALIKA & 1969 & UP-2121 & 1986 & VL-892 & 2008 \\
\hline NP-830 & $1958-62$ & SONORA-64 & 1967 & VL-616 & 1986 & DBW-88 & 2014 \\
\hline RAJ-4125 & & UP-262 & 1978 & WH-291 & 1985 & WH-1080 & 2011 \\
\hline RIDLEY & 1954 & WH-147 & 1978 & WH-542 & 1992 & HD-2967 & 2011 \\
\hline WH-331 & & WL-711 & 1977 & HUW-206 & 1985 & HS-490 & 2009 \\
\hline
\end{tabular}

help to develop grains that have a low or zero content of immunotoxic sequences, but with reasonable baking quality.ICAR-IIWBR, Karnal has initiated a study to identify wheat varieties with low $\mathrm{CD}$ toxicity which can be used in breeding program.

For this study, 80 wheat varieties released in India during different periods were used (Suppl Table 1). These were grown at ICAR-IIWBR farm during the crop season 2017-18. Two genotypes each of rice and maize were purchased from the local market and used as negative controls. The flours were prepared using Cyclotec mill (FOSS) with $0.5 \mathrm{~mm}$ screen. The alcohol soluble prolaminswere extracted in $60 \%$ ethanol and quantified by Bradford Method. The dilutions of the antigen, primary antibody (Pierce Gliadinpeptide Antibody, 4F3, 1:4000) and secondary antibody (Pierce Goat Anti-Mouse IgG, peroxidase conjugated, 1:10000) were standardized using the standard checker board method. Equal amount of extracted protein of each sample was subjected to the standardized Indirect ELISA protocol as used by Gregorini et al. (2009).The ELISA results were adjusted with the total prolamin content of each sample and the relative reactivity against the antibody was calculated. ANOVA and Tukey'scomparison test were performed using XLSTAT.The ELISA results were further confirmed by western blotting using same antibody.

Monoclonal antibodies have been used in many studies to show the presence of $\mathrm{CD}$ toxic sequences in protein fractions of cereals like wheat, barley and oats (SpaenijDekking et al., 2005; Gregorini et al., 2009; Ribeiro et al., 2016). In this study monoclonal antibody against the -gliadin peptides p58-73 (KLQPFPQPELPYPQPQ) containing a core region reported for $\mathrm{CD}$ toxicity was used for the indirect ELISA for screening the wheat genotypes for the presence of these toxic sequences. The presence of $\mathrm{CD}$ toxic epitopes was also confirmed by western blotting. Around 3-fold variability (2.1-6.0) was observed for this specific (Glia - 2) CD toxic epitope in wheatvarieties across 
the periods (Table 2). The results showed that most of the varieties developed before 1960 hadsignificantly low antibody reactivity (3.25). However,after 1960 varietal differences were observed but overall no significant change observed in antibody reactivity in the wheat varieties released in last 60 years in India.Some wheat varieties with low reactivity have been identified across the periods (JOB-666, BAXI-288-18, NI-345, NP 830, C 591, Khenpad 25, HD 2329, HI 977, HS 240, K 9644). But further confirmation is required in the second year and also with antibodies against different epitopes.Some other studies have also reported that the ancient wheat

Table 2 Relative antibody reactivity against CD toxic epitopes in wheat varieties released during different periods.

\begin{tabular}{lcccc}
\hline Period & $\begin{array}{c}\text { Before } \\
\mathbf{1 9 6 0}\end{array}$ & $\mathbf{1 9 6 1 - 1 9 8 0}$ & $\mathbf{1 9 8 1 - 2 0 0 0}$ & $\begin{array}{c}\text { After } \\
\mathbf{2 0 0 0}\end{array}$ \\
\hline Range & $2.1-4.9$ & $3.1-5.2$ & $2.8-6.0$ & $2.5-5.8$ \\
Mean* & $3.25 \mathrm{~b}$ & $4.10 \mathrm{a}$ & $3.98 \mathrm{ab}$ & $4.03 \mathrm{a}$ \\
\hline
\end{tabular}

*Mean of 20 wheat varieties. Means with the same letter in the same row are not significantly different $(\mathrm{P}<0.05)$

varieties have less number of $\mathrm{CD}$ toxic epitopes and these might be better to be used in the diets of people suffering from celiac disease (van den Broeck et al., 2010). Contrasting studies suggesting that the modern wheat varieties instead of ancient varieties have fewer CD toxic epitopes (Colombo and Gregorini, 2012;Prandi et al., 2017) have also beenreported. While Malalgoda et al. (2018) reported that there is no association between the cultivar release year and the amount of immunogenic epitopes and -gliadin. Ribeiro et al. (2016) have predicted that breeding has not contributed to the prevalence of CD immune stimulatory epitopes. Mohan Kumar et al. (2017) reported that the tetraploid wheat varieties are less immune reactive as compared to the hexaploids. Shewry (2018) reviewed the studies on CD and found that wide range of variation exits in reactions among genotypes of all species. However, it was pointed that these studies used only one to four antibodies which target only a small proportion of the total number of celiac epitopes in gluten proteins.

The presence of CD epitopes was also confirmed by the western blotting. Representative samples with low and high relative reactivity based on ELISA result were selected. Equal quantity of these samples were used for SDS-PAGE and further detected with the $4 \mathrm{~F} 3$ antibody.

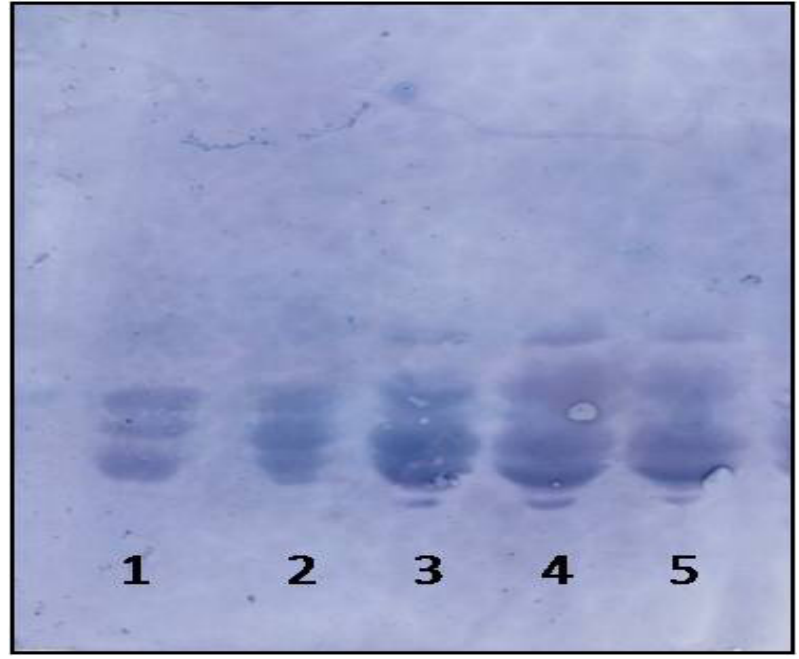

Fig 1. Immunoblotting of gliadin extracts with $4 \mathrm{~F} 3$ monoclonal antibody. 1and 2 - low antibody reactivity; 3,4 and 5 high antibody reactivity.

The intensity of bands clearly showed the relative reactivity of the wheat genotypes (Fig 1).Other studies have also reported such confirmation of ELISA results by western blotting (Gregorini et al, 2009; Spaenij-Dekking et al., 2005).

The conflicting results on the immunogenicity of ancient and modern wheat varieties highlights the need to screen the large wheat germplasm available including different wheat species, wild relatives and synthetics. The identified genotypes with low CD toxicity can be used in breeding programmes for reducing CD toxic epitopes in high yielding varieties. This study is a very small initiative where only one monoclonal antibody against few epitopes has been used. More monoclonal antibodies can be used in future studiesto target more CD toxic epitopes. The most important challenge while developing a new genotype with low $\mathrm{CD}$ toxicity either by breeding or genetic engineering will be to keep the baking and processing quality of the wheat intact.This will bring less CD toxic wheat products in food chain with consequences of reduced celiac disease.

\section{Acknowledgement}

This study was supported by Department of Biotechnology, New Delhi, India funded research project No. BT/ PR7186/FNS/20/702/2012DT. 21.06.2014

\section{References}

1. Colomba, MS, and A Gregorini 2012. Are ancient durum wheats less toxic to celiac patients? A study 
of alpha-gliadin from Graziellara and Kamut. The Scientific World Journal, 8; 837416,1-8.

2. Gregorini A, M Colomba, HJ Ellis, and PJ Ciclitira. 2009. Immunogenicity characterization of two ancient wheat -gliadin peptides related to celiac disease. Nutrients 1;276-290.

3. Malalgoda M, F Manthey and S Simsek 2017. Reducing the celiac disease antigenicity of wheat. Cereal Chemistry. 95;49-58.

4. Malalgoda M, SW Meinhardt and S Simsek, 2018. Detection and quantitation of immunogenic epitopes related to celiac disease in historical and modern hard red spring wheat cultivars. Food Chemistry. 264;101-107.

5. McAllister BP, E Williams, and K Clarke, 2019. A Comprehensive Review of Celiac Disease/GlutenSensitive Enteropathies. Clinical reviewes in allergy and immunology. 57(2);226-243.

6. Mohan Kumar, BV, UJS Prasada Rao, and P Prabhasankar. 2017. Immunogenicity characterization of hexaploid and tetraploidwheat varieties related to celiac disease and wheat allergy. Food and Agricultural Immunology. 28;888-903.

7. Pilolli R, A Gadaleta, G Mamone, D Nigro, De E Angelis, N Montemurro, and L Monaci 2019. Scouting for Naturally Low-Toxicity Wheat Genotypes by a Multidisciplinary Approach. Scientific Reports. 9(1);1646.

8. Prandi B, T Tedeschi, S Folloni, G Galaverna, and S Sforza 2017. Peptides from gluten digestion: A comparison between old and modern wheat varieties. Food Research International. 91;92-102.

9. Ramakrishna et al., 2016 Prevalence of Adult Celiac Disease in India: Regional Variations and Associations. American Journal of Gastroenterology. 11;115-123.
10. Ribeiro, M, M Rodroguez-Quijano, FM Nunes, JM Carillo, G Branlard and G Igrejas. 2016. New insights into wheat toxicity: breeding does not seem to contribute to a prevalence of potential celiac disease's immunostimulatory epitopes. Food Chemistry 213;8-18.

11. Scherf, KA, H Weiser, and P Koehler. 2018. Novel approaches for enzymatic gluten degradation to create high-quality gluten-free products. Food Research International. 110; 62-72.

12. Shewry PR, 2018. Do ancient types of wheat have health benefits compared with modern bread wheat? Journal of Cereal Science, 79, 469-476.

13. Shan L, O Molberg, I Parrot, F Hausch, F Filiz, GM Gray, LM Sollid, and Khosla, C.2002. Structural basis for gluten intolerance in celiac sprue. Science 297; 2275-2279.

14. Singh P, A Arora, TA Strand, DA Leffler, C. Catassi, et al., 2018. Global Prevalence of Celiac Disease: Systematic Review and Meta-analysis. Clinical Gastroenterology and Hepatology. 16; 823-836.

15. Spaenij-Dekking L, Y Kooy-Winkelaar, PV Veelen, JW Drijfhout, H Jonker, et al., 2005. Natural variation in toxicity of wheat: Potential for selection of nontoxic varieties for celiac disease patients. Gastroenterology. 129; 797-806.

16. Van den Broeck HC, HC de Jong, EMJ Salentijn, L Dekking, D Bosch, Hamer, RJ and MJM Smulders. 2010. Presence of celiac disease epitopes in modern and old hexaploid wheat varieties: wheat breeding may have contributed to increased prevalence of celiac disease. Theoretical and Applied Genetics. 121; 1527-1539. 